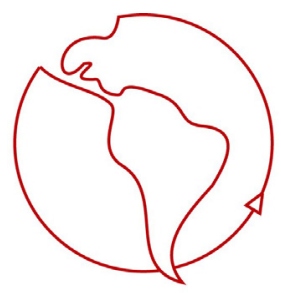

\title{
Nuevas Exclusiones en la Complejidad Social Contemporánea: Un Comentario desde el Paradigma del Capital Social
}

John Durston Wagner

Ex-funcionario CEPAL, consultor e investigador independiente

Para comentar las exposiciones de los profesores Marcelo Arnold, Rolf Foerster, Vicente Espinoza, Ana María Raad, Gabriel Guajardo y Paulina Osorio ${ }^{1}$, voy a comenzar con algunas reflexiones sobre el concepto de exclusión social.

Lo que queda claro es que todos excluimos y todos somos excluidos, eso es un concepto básico de la antropología. La identidad se define en parte en oposición al 'otro' diferente, lo excluimos de nuestra identidad, y lo excluimos también en muchas otras cosas. También somos excluidos: yo llevo treinta años aquí y sigo siendo yanqui, no soy chileno, no pertenezco a esa identidad, soy excluido de ello. También nos autoexcluimos. Un antropólogo que fue profesor mío a los setenta y cinco años me habló de todas las cosas que querría hacer "cuando yo sea viejo." El se autoexcluía de la categoría de viejo que las demás personas le asignaban.

Pero también hay aspectos de la exclusión que constituyen un problema social. Yo creo que es ése tipo de exclusión que se quiere dirigir la atención en este evento, en este curso. ¿Cuándo es un problema? Cuando sistemáticamente y permanentemente una categoría de personas es excluida del acceso al poder. Y en ese sentido, en la descripción de Vicente Espinoza de los mecanismos de desigualdad en la sociedad chilena hay elementos fuertes de exclusión social.

La moda en torno al concepto de exclusión social comenzó unas décadas atrás en Europa, y en ella la exclusión social inicialmente hacía referencia a personas que quedaron fuera del Estado Benefactor, de los derechos que éste otorgaba en cuanto a acceso a beneficios materiales. Ese tipo de excusión social de tipo europeo, era de una minoría, cuya exclusión podía llamarse total. Se trata de la gente que no tiene acceso a nada, que no tiene la posibilidad de participar en nada, producto de la desaceleración del crecimiento y los inadecuados recursos para mantener el Estado Benefactor de antaño.

En contraste, en América Latina y en Chile, como la cobertura adecuada en salud, jubilación, etc., nunca llego a la mayoría, la exclusión puede aplicarse a mayorías. Cuando hablamos de la 'clase media' se tiene una imagen de un estilo de vida cercano al europeo, que realmente corresponde a una minoría privilegiada. Entonces hay argumentos de que en Chile, en muchos sentidos, son excluidas las mayorías, todavía. Por ende, es una exclusión que no es tan completa como la exclusión europea, de los pocos que cayeron fuera de la red social y viven absolutamente marginalmente. Más bien, como lo define Deepa Narayan en los "países en vías de desarrollo", la exclusión es la ausencia del acceso completo a la ciudadanía; o sea, una exclusión relativa. Y en eso las diferentes exposiciones han aclarado algunas de los proceso de exclusión social relativa que operan en Chile actualmente. Creo que necesitamos dedicar mucha atención a esos procesos, a desempaquetarlos, a examinar las formas en que se reproducen las desigualdades sociales y los privilegios, y quiénes son los agentes de estos procesos de exclusión.

\footnotetext{
${ }^{1}$ Ver los otros artículos en este número de la revista MAD con las exposiciones del Seminario "Nuevas exclusiones en la complejidad social contemporánea", realizado el día 29 de julio 2005, y coordinado por el profesor Daniel Duhart del Magíster de Antropología y Desarrollo de la Universidad de Chile.
} 
¿Qué tiene que ver todo esto con capital social? La definición que yo uso del capital social es la que usa la CEPAL. Se define, en el terreno de los comportamientos, como las relaciones y las instituciones sociales que tienen contenidos de cooperación y que son fortalecidos por actitudes de confianza. Narayan también define el capital social en términos de vínculos, lazos: 'los lazos que unen', dice ella, 'también excluyen'. En un grupo en que hay confianza, en que hay costumbres y repeticiones de cooperación basadas en experiencias positivas en el pasado, también hay una exclusión.

Es importante no solo hablar del capital social de los pobres, de las redes de ayuda mutua y de supervivencia, sino hay que prestar atención al capital social de los ricos, de los grupos privilegiados o que ostentan posiciones de poder. Pierre Bourdieu utiliza una definición de capital social en que hace explícito que estas relaciones son las que dan acceso a bienes materiales y a poder. Esto es muy importante en relación al tema de exclusión porque los estudios de Bourdieu profundizan en las formas en que grupos familiares, sectores socioculturales, y clases dominantes reproducen sus privilegios mediante la exclusión de todos los demás, o mediante la movilidad limitada, individual, gradual, filtrada, de personas de los sectores subordinados.

Hay otro aspecto importante de la discusión que tenemos esta noche, que es la relación entre exclusión y subordinación. Si la exclusión es relativa, entonces hay un grado de inclusión también. Pero la exclusión es un problema en la medida en que hay una forma de subordinación que involucra una limitación del acceso al poder o a los bienes materiales, y eso es algo que hemos visto en estas exposiciones en diferentes ámbitos. Quizás uno de los aspectos o conceptos del paradigma del capital social que también puede ser útil en el análisis de estas exposiciones, es los dos tipos ideales propiedad de capital social, de "ownership". ¿Quién posee una relación social, quién es el propietario de ese capital intangible?

Una relación social siempre tiene dos propietarios: los dos participantes de la relación, aunque con cuotas diferentes de propiedad o control sobre esta relación. Cuando se trata de una institución social, de instituciones cívicas como las que analizó, en el caso de Italia, Robert Putnam, toda la población, toda la comunidad, comparte la propiedad y el acceso a los beneficios de ese capital social.

Simplificando para el propósito del análisis, podríamos sugerir que el capital social individual es el que predomina en el capital social de los ricos, y que en el caso de los pobres la fuerza están en los números, el capital está en una coordinación, una participación, en una institución que no es simplemente un sistema de redes.

Incluso la extensión de las redes de relaciones personales en la forma de clientelismo político es una forma de capital social tanto para los patrones como para los clientes. Pero evidentemente es instrumental para la reproducción de un sistema de exclusión relativa, pero de alto grado de control de la sociedad por una élite.

Los matices que pueden tener las formas de exclusión son muy diferentes en los diversos casos que se han expuesto: Pueblos indígenas, diferentes clases y estratos sociales, los homosexuales, los mayores de edad, y los excluidos de la modernidad digital. Pero como decía Daniel Duhart, hay elementos comunes también. En algunos casos hay elementos de autoexclusión, en otros parte de la exclusión es la invisibilidad o el silencio sobre la existencia de un grupo excluido. Este elemento de silencio que se abordó en la presentación sobre el caso de los homosexuales, también ha operado en el caso de los pueblos indígenas. Parte de la idea del Estado Nación que ha predominado y sigue predominado hoy en Chile, es que ser indígena es ser algo negativo y contrario a la identidad nacional. En muchos discursos privados de funcionarios públicos esto se repite como una expresión aprendida del ilustrismo. La idea eurocéntrica de que la educación formal y el conocimiento europeo es la base de la única ciudadanía moderna, la única identidad viable es también la negación y la exclusión de otros pueblos y de otras naciones. Y hasta hace 
muy poco había un intento de invisibilizarlos, de declarar que los pueblos indígenas se habían destruido y que eran simplemente un recuerdo.

El tema es importante no solo para un fin académico de entender mejor cómo funciona la sociedad, cómo se reproduce, sino implícitamente en estas exposiciones hay un deseo de pensar sobre cómo cambiar. ¿Cómo cambiar qué? Como cambiar el sistema sociopolítico-económico y cultural. Allí el concepto de capital social sólo tiene relevancia como una pequeña parte de un enfoque de actores sociales, y eso a su vez dentro de una visión de la sociedad como un sistema complejo basado en múltiples agentes. Si pensamos en la sociedad con todas estas otras facetas, que incluyen lo simbólico, lo cultural, lo económico, etc., se ve como un solo sistema parecido a un ecosistema. Todos los agentes o actores desarrollan estrategias para lograr sus objetivos y la misma estructura del sistema evoluciona y cambia a la medida en que co-evolucionan las estrategias de estos actores. El manejo del capital social como uno de los activos de cada agente, sea individuo o grupo, produce estas instituciones y estructuras más complejas.

El problema que ha sido planteado un poco pesimísticamente por Vicente Espinoza es cómo se puede cambiar las formas presentes de reproducción de la exclusión relativa, léase desigualdad. El plantea correctamente que hay muchas evidencias en que capital social de los pobres, a nivel comunitario, no lleva a ningún cambio en el sistema mismo, en que son centrales las relaciones de clientelismo. Éste se entiende como una relación de intercambio personalizada que articula clases sociales dominantes con dominados. Esa forma de relacionarse, que legitima la desigualad y la exclusión parcial, es un elemento de estabilidad en el sistema. Pero la teoría de los sistemas complejos nos enseñanza también que cualquier sistema es estable solo mientras no recibe un "shock" que, en forma impredecible, produce una transición a otra estadía del sistema.

En el caso de la diferentes identidades excluidas que hemos visto y escuchado en las exposiciones de hoy, se nota la ausencia de un tipo de capital social que se ha definido como "bridging", o sea capital social de puente, entre pequeñas identidades y asociaciones-organizaciones micro-locales, léase de barrio, comunidades campesinas, y la emergencia de actores colectivos más grandes. O sea estamos hablando de la relativa ausencia de movimientos sociales como se conocía en el pasado: por ejemplo en el movimiento sindical. Sin embargo, estos movimientos, como formas más masivas de capital social popular, si bien desaparecen durante largos períodos, dejan un aprendizaje social acumulativo que los permite resurgir cuando hay contextos favorables y alianzas que permiten que estas formas de capital social produzcan un "shock" a un sistema que reproduce la exclusión.

El movimiento mapuche es probablemente uno de los más notables. A nivel comunal (que no es local sino es un sistema sociopolítico-territorial en sí), a nivel regional y a nivel nacional, se ha producido un grado de presión que está logrando cambios en las estrategias de otros actores, y por ende posibilidades de cambio en el sistema. Eso puede verse también en cuanto a otros actores potenciales. Cómo pasar de excluido a ser actor social en la forma de un movimiento colectivo mayor es lo que puede aportar este escrutinio profundo de diferentes tipos de exclusión.

Generalmente se pone énfasis en que los lazos fuertes en una comunidad cerrada no son muy útiles, porque son redundantes en el tipo de recursos a los cuáles dan acceso, y por ende los lazos con personas más distantes que tienen otros recursos es importante. Vicente Espinoza puso el acento donde debe estar: donde hay pobreza los lazos fuertes no sirven tanto. Pero si mi hermano es dueño de un banco, ese lazo fuerte me sirve, y trato de limitar y controlar, y poner reglas, a los lazos débiles que tengo con personas de situaciones sociales menos ventajosas. Entonces, para mí, Granovetter no desarrolla totalmente el análisis. Hay en los estudios de capital social una escuela en particular que ve a los Estados Unidos como una sociedad sin clases sociales, donde las estratificaciones son tan tajantes, donde hay movilidad, y si hay exclusión debe ser un tipo de autoexclusión, exagerando un poco ese tipo de análisis. Pero para mí 
justamente el punto es que hay identidades fuertes e identidades débiles. Las fuertes son las que, en términos de Bourdieu, dan acceso a recursos valorados por todos, y excluyen de ese acceso a los que no pertenecen al círculo de los favorecidos de la elite: esto es obviamente el capital social de los ricos. Una identidad fuerte también es la identidad étnica, lo que nos lleva al tema del racismo. La vejez, creo, es una identidad débil, en el sentido de que es más importante el estrato socioeconómico del viejo que la vejez en sí, en términos de poder, en términos de exclusión. Un "viejo rico" no está realmente excluido en los términos en que se ha usado el concepto aquí.

Finalmente, el concepto de actor político ha estado implícito en la discusión sobre clientelismo, y justamente tal como Vicente Espinoza señaló que en los años noventa se reprodujo un sistema, con algunas diferencias, en que esta relación personalizada, descrito y analizado por Valenzuela en Chile, y últimamente en Argentina por Auyero, a mí parece ha ido cobrando fuerza en los partidos de la Concertación. Creo que en dos o tres momentos críticos, los partidos de la concertación optaron por mantener este sistema y fortalecerlo, por una suerte de "miedo a los pobres". Eso sería también tema de largo análisis: ¿Cómo emergió eso, por qué había miedo al desorden, por qué se sigue reproduciendo eso? Pero creo que si bien al interior de cada partido político hay sectores que están allí porque manejan maquinas clientelistas y quieren reproducir esa forma de subordinación en que hay una exclusión parcial, también hay sectores reformistas, democratizantes, que están en la lucha por controlar los partidos. Se puede ser optimista o pesimista en cuanto al desenlace de eso, pero es importante mirar más cercanamente a esa lucha al interior de los partidos y al miedo al cambio, el miedo de que el sistema cambie.

Ese tipo de "shock" ocurre, tal como dijo Gabriel Guajardo, cuando hay un sentimiento de urgencia, cuando hay SIDA, cuando hay violencia. Irónicamente parece que la violencia es una de las pocas formas de acción que produce una reacción del sistema rápida para mitigar la exclusión. Produjo en el caso indígena intentos por contener, por darles una alternativa, por cooptar también al movimiento. Lo que es impredecible es como esos intentos de reacción co-evolucionan con las estrategias de los diversos actores en el poder y fuera de poder estatal: inevitablemente lleva a cambios en el sistema, que son impredecibles, pero fascinantes de analizar y estudiar. 